\title{
Seasonality of spatial patterns of abundance, biomass and biodiversity in a demersal community of the
} NW Mediterranean Sea

Daniel Vilas ${ }^{* 1,2,3}$, Maria Grazia Pennino ${ }^{4,5,7}$, Jose Maria Bellido ${ }^{6,7}$, Joan Navarro ${ }^{1}$, Isabel Palomera ${ }^{1}$, Marta Coll ${ }^{1}$

${ }^{1}$ Institut de Ciències del Mar (ICM-CSIC), P. Marítim de la Barceloneta, 37-49, 08003 Barcelona, Spain.

${ }^{2}$ Nature Coast Biological Station, Institute of Food and Agricultural Sciences, University of Florida, Cedar Key, FL 32625, United States

${ }^{3}$ Fisheries and Aquatic Sciences Program, School of Forest Resources and Conservation, University of Florida, Gainesville, FL 32611, United States

${ }^{4}$ Fishing Ecology Management and Economics (FEME) - Universidade Federal do Rio Grande do Norte UFRN. Depto. de Ecologia, Natal (RN) - Brazil.

${ }^{5}$ Instituto Español de Oceanografía, Centro Oceanográfico de Vigo, Av. da Beiramar, 37, 36202 Vigo, Pontevedra, Spain

${ }^{6}$ Instituto Español de Oceanografía, Centro Oceanográfico de Murcia C/Varadero 1, 30740 San Pedro del Pinatar, Murcia, Spain.

${ }^{7}$ Statistical Modeling Ecology Group (SMEG). Departament d'Estadística i Investigació Operativa, Universitat de València. C/Dr. Moliner 50, 46100 Burjassot, Valencia, Spain.

*Corresponding author: danielvilasgonzalez@gmail.com

\begin{abstract}
Information on the spatial patterns and habitat preferences of marine species is key to understand the functioning of marine ecosystem and to manage and protect marine resources efficiently. However, the study of spatial patterns of marine ecosystems is challenging because they are dynamic environments that can vary seasonally. We analysed the spatial patterns of abundance, biomass, and biodiversity (richness and Shannon indices) of a northwestern Mediterranean demersal community and changes in these patterns between two different seasons. We modelled observed spatial patterns by season using hierarchical Bayesian spatial models and environmental, physical and anthropogenic factors. We identified the main drivers of fish, cephalopods, crustaceans and demersal assemblage spatial and seasonal patterns. Overall, our findings revealed the importance of seasonality in the spatial patterns of the demersal community, which were mainly driven by sea surface temperature. Results also underlined important patterns of movements of demersal organisms: fishes showed a general move from the upper-slope in winter to the continental shelf in summer, cephalopods showed a move from the northern part of the study area in winter to the southern part in summer, and crustaceans showed high densities in the area surrounding the Ebro Delta River in winter mainly driven by species-specific behaviour. Our results are relevant to inform future management measures
\end{abstract}


in the study area, such as seasonal fishing restrictions to protect specific aggregations of organisms during reproduction or feeding, or to adapt local marine protected areas to seasonal processes. This study provides evidence of the need to expand current monitoring schemes to capture the seasonality of marine demersal communities for a more comprehensive marine spatial planning framework.

Keywords: Bayesian analysis, Mediterranean Sea, seasonal patterns, spatial ecology, species distribution models, temperature.

\section{Introduction}

Marine biodiversity is key for the functioning of marine ecosystems (Hooper et al., 2005; Worm et al., 2006), and plays an important role in relation to ecosystem services (Pauly et al., 2002; Liquete et al., 2013). It is therefore crucial to understand the biogeographic patterns and the spatial and temporal dynamics of marine species and communities to advance our knowledge about the functioning of marine ecosystems (Duffy, 2009; Armstrong et al., 2012). This knowledge is essential to predict the impacts of climate change and anthropogenic activities on marine ecosystems, and to contribute to the effective management of marine resources based on marine spatial planning (Navarro et al., 2015).

The Mediterranean Sea, with an area of 2,500,000 $\mathrm{km}^{2}$, is the largest semi-enclosed sea in the world (Margalef, 1985). It is surrounded by Africa, Europe and Asia, and is a marine biodiversity hotspot (Bianchi and Morri, 2000; Myers et al., 2000; Coll et al., 2010). Most Mediterranean marine ecosystems are seriously impacted by the effects of anthropogenic activities, such as fishing, coastal degradation and pollution (Coll et al., 2010; Navarro et al., 2015). A high proportion of commercial demersal species are currently highly fished or overfished (Sardà et al., 1998; Colloca et al., 2013; Tsikliras et al., 2015) and several demersal non-commercial species have declined in both abundance and biomass (Coll et al., 2010; Ferretti et al., 2010; Piroddi et al., 2017). In particular, the development of fishing technologies, excessive fishing effort, and the increasing demand for marine resources is placing intensive pressure on Mediterranean marine resources (Coll et al. 2013). Because of that, fishing, particularly bottom trawling, is considered one of the main factors shaping the demersal and benthic community (De Juan et al., 2007) and so it should be included in spatio-temporal analysis of benthic ecosystems.

Several studies have analysed the spatial distribution and patterns of marine species (Morfin et al., 2012; Pennino et al., 2013; Mendoza et al., 2014; Saraux et al., 2014; Navarro et al., 2016) or community properties (Coll et al., 2010; Navarro et al., 2015; Puerta et al., 2015) in the NW Mediterranean with an annual or aggregated temporal resolution. According to available results, the distribution patterns of these species vary as a result of environmental factors (Abelló et al., 2002; Navarro et al., 2015), oceanographic conditions (Gibson et al., 2005; Canals et al., 2009) and biological and anthropogenic factors (Navarro et al., 2015). The bathymetric gradient has been considered the key factor in the distribution and association of 
these species (d'Onghia et al., 2004; Massutí and Reñones, 2005). However, these factors can affect the distribution patterns of marine organisms in different ways because of the intrinsic features of each taxon (Ward and Myers, 2005). The only exception that analysed the seasonal distribution of the demersal marine community in the western Mediterranean Sea is the study by Gaertner (2000). This study was based on a seasonal dataset using a Partial Triadic Analysis (PTA) framework and that described strong stability in the demersal assemblage spatial patterns in the Gulf of Lions, with the exception of a few fish species including four-spotted goby (Deltentosteus quadrimaculatus) and red mullet (Mullus barbatus).

Importantly, the main factors that affect the distribution, abundance and biomass of demersal species vary seasonally (Bosc et al., 2004; Hauck, 2018). In the Mediterranean Sea, seasonal changes are clearly driven by two different periods that can be distinguished by the establishment or disappearance of a thermocline. The seasonal stratification of surface waters is a common feature across the Mediterranean Sea (Salat et al., 2002a). The seasonal thermocline is well-defined with a strong separation between early spring and late autumn, when there is no mixing of the water column. On the contrary, in winter the thermocline disappears due to strong local winds (from the northeast). This oceanographic feature induces the vertical mixing of the water column, and the vertical diffusion of nutrients to the surface (Salat et al., 2002a). These two seasons are characterised by different environmental factors (Salat et al., 2002a) and likely have impacts on the dynamics of the whole community, including the demersal community.

Here, we quantify the spatial patterns of the demersal community (separated into fishes, cephalopods and crustaceans) in a productive and highly exploited area of the northwestern Mediterranean Sea (NW Mediterranean Sea) during two different seasons. In particular, we analysed the seasonal patterns of abundance, biomass and biodiversity from the continental shelf and upper slope (depth range between 50 to 350 metres) of the Southern Catalan Sea (Balearic Sea, NW Mediterranean Sea). Our analyses were based on the use of fine-scale data collected during two oceanographic campaigns in the study area (winter and summer 2013) and the use of Bayesian Species Distribution Models (BSDMs) (Wikle, 2003), which are suitable statistical tools to quantify the distribution of species using environmental conditions and fishing pressure as predictors (Golding and Purse, 2016). Applying BSDMs, we identified which environmental and physical factors, including sea surface temperature (SST), sea bottom temperature (SBT), fluorescence (Chl), sea surface salinity (SSS), type of substrate and depth, in addition to anthropogenic pressures (coastal-based impacts and fishing effort), or a combination of them, could best predict the seasonal spatial patterns of the biological variables. This is the first study that analyses the seasonal distribution of the demersal marine community in the western Mediterranean Sea and investigates the main drivers by implementing a Bayesian approach.

\section{Methods}
a) Study area 
This study was conducted on the continental shelf and upper slope (ranging from 50 to 200 and 200 to 350 meters, respectively) of the Southern Catalan Sea, adjacent to the Ebro River Delta, between Barcelona and Castelló de la Plana, in the NW Mediterranean Sea (Fig. 1a). The study area covers approximately $10,000 \mathrm{~km}^{2}$, with a depth range between 35 and 350 metres. The region is characterised, in contrast to most of the Mediterranean Sea, by a wide continental shelf and a relatively higher primary production due to the effect of the Liguro-Provenzal-Catalan current (recently named the North current) and the discharge of Ebro River Delta (Estrada, 1996). The study area is mainly oligotrophic, but local enrichment occurs due to regional environmental events, mainly related to wind conditions during winter, the existence of a temporal thermocline and a shelf-slope current and river discharges (Agostini and Bakun, 2002) (Fig 1b).
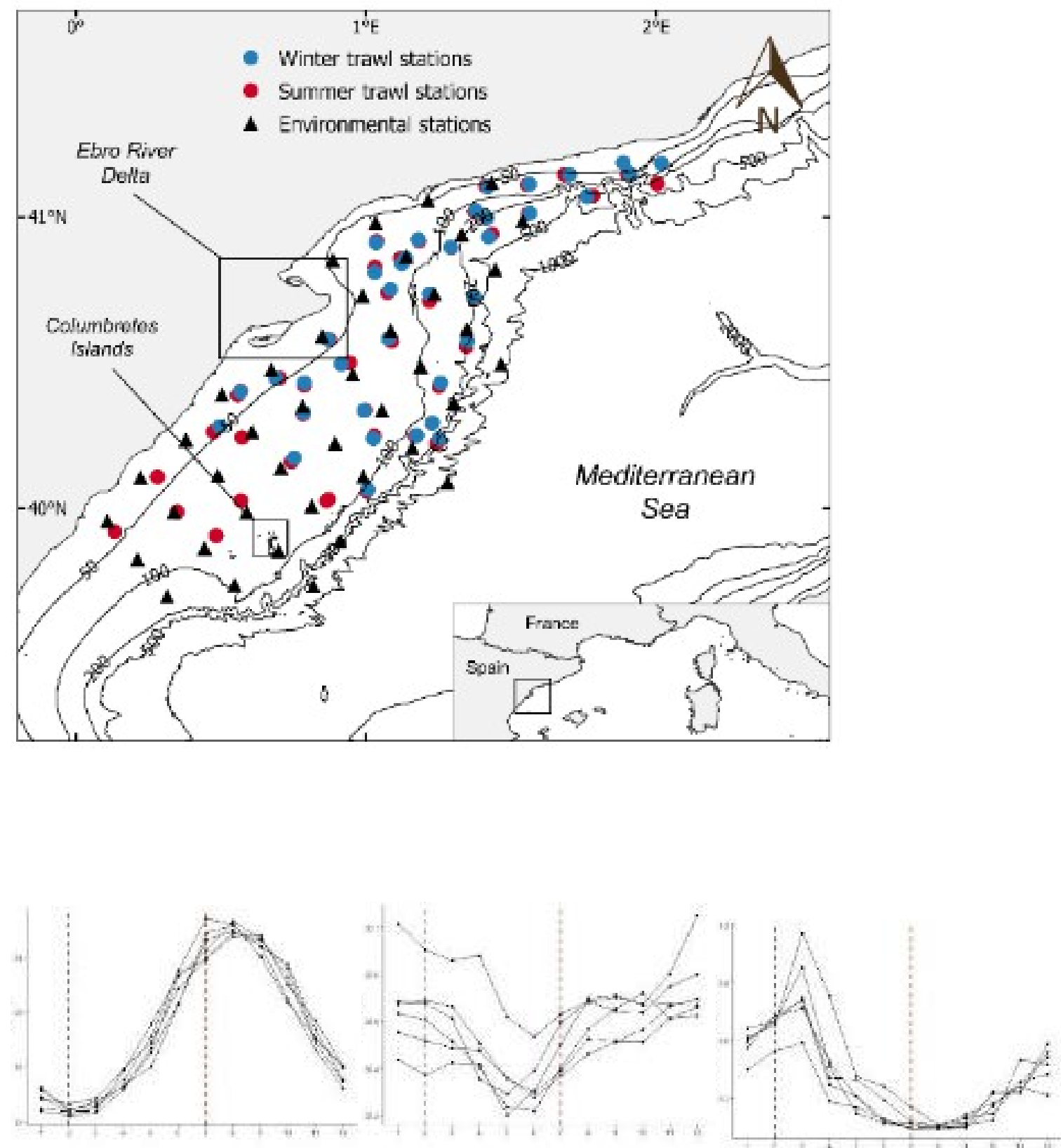
Figure 1. a) Study area located in the Catalan Sea, NW Mediterranean Sea, and trawling sampling stations for both seasons (blue bullets: winter; red bullets: summer) and environmental stations (black triangles) during the scientific survey ECOTRANS (2013). b) Monthly sea surface temperature (SST) (2010-2015), sea surface salinity (2008-2013) (SSS), and fluorescence (2010-2015) in the study area, and winter survey (blue dash line) and summer survey (red dash line) (source: http://mcc.jrc.ec.europa.eu/emis/).

\section{b) Sampling of the demersal community}

The biological data used in this study were collected during two scientific surveys developed within the Spanish National Project ECOTRANS (Palomera et al., 2015). Two scientific demersal trawling surveys on board the oceanographic vessel R/V Ángeles Alvariño were carried out in 2013 during winter (22 February 7 March) and summer (2 - 16 July). Samples were collected from 37 and 45 sampling sites, respectively

(Fig. 1a). These sampling sites were distributed randomly in the study area on the continental shelf and upper slope (depth range between 50 and 350 metres). A standard bottom trawling otter-gear (GOC 73 sampling trawl) ( $3 \times 16 \mathrm{~m}$, mesh size $20 \mathrm{~mm}$ ) was used during 30-60 minutes based on the MEDITS sampling protocol for bottom trawling (Bertrand et al., 2002a).

During the surveys, all marine organisms were classified and identified (see Appendix 2 in supporting information), and the abundance and biomass were calculated for each species. These data were standardized to the number of individuals $\mathrm{km}^{-2}$ and $\mathrm{kg} \cdot \mathrm{km}^{-2}$, respectively, taking into account the swept area for every sampling station.

\section{c) Estimates of abundance, biomass and biodiversity}

From the survey dataset, we calculated the abundance $\left(\mathrm{n}^{\mathrm{o}}\right.$ individuals $\left.\cdot \mathrm{km}^{-2}\right)$, biomass $\left(\mathrm{kg} \cdot \mathrm{km}^{-2}\right)$, species richness $\left(\mathrm{n}^{\mathrm{o}}\right.$ species $\left.\mathrm{km}^{-2}\right)$ and the Shannon index $\left(\mathrm{H}^{\prime}\right)$ of the demersal community, including all fish, cephalopods and crustacean species, and for each group separately. Firstly, the species abundances and biomasses were calculated for individual sampling stations by season and by species group (fish, cephalopod 
and crustacean). These estimates were then added in order to calculate the total abundance and biomass of the demersal community per sampling station by season. Overall averages of abundance and biomasses as well as standard deviations (sd) and medians were calculated for the whole study area to summarize the biological data for every group and season. Secondly, we calculated the species richness and the Shannon index for fishes, cephalopods, crustaceans and for the total demersal community. These calculations were done with PRIMER in PERMANOVA V.7 (PRIMER-E Ltd., Plymouth, UK) (Clarke and Gorley, 2015).

In terms of biodiversity indicators, we chose two indexes to describe species diversity (Pavoine and Bonsall, 2011). We selected species richness because it is the simplest way to describe community and regional diversity (Magurran, 1988). Moreover, it is based on the number of species present at a site. Furthermore, the Shannon index of biodiversity was selected because it is one of the most widely used for the analysis of biodiversity. The Shannon index index is a cardinal index and treats each species as equal, so it is more effective with similar organisms (Shannon and Weaver, 1949). As with the abundance and biomass estimates, the biodiversity indexes were summarized with the average, median and sd for the study area in both seasons.

Kruskal-Wallis statistical tests were used to test significant differences between the two seasons, considering biological data in terms of abundance, biomass, Shannon index and richness for the whole demersal community and for fishes, cephalopods and crustaceans. Additionally, Welch tests were used to test significant differences between two seasons in the case of not accomplishing Kruskal-Wallis test assumption of homogeneity of variance.

\section{d) Environmental and anthropogenic variables}

Nine explanatory variables were used to explore the response of the distribution of demersal assemblage in terms of abundance, biomass and biodiversity (whole community, and fishes, cephalopods and crustaceans, separately) to environmental and anthropogenic pressures. Environmental variables included (1) Sea Surface Temperature (SST, ${ }^{\circ} \mathrm{C}$ ), (2) Sea Bottom Temperature (SBT, ${ }^{\circ} \mathrm{C}$ ), (3) Sea Surface Salinity (SSS, PPS), (4) fluorescence ( $\left.\mu \mathrm{g} \mathrm{Chl} \cdot 1^{-1}\right)$, (5) depth (m), and (6) type of substrate (fine mud, sand and sandy mud), in addition to season (winter or summer) (Table 1). All of these environmental factors except for "type of substrate" were collected during the experimental survey for each season. The type of substrate was downloaded from the EMODnet website (http://www.emodnet-seabedhabitats.eu/).

Regarding anthropogenic variables, we used (1) a cumulative index of coastal-based impacts and (2) an estimate of fishing effort (Table 1) (see Appendix 1 Fig. S1.2). The cumulative index of coastal-based impacts is a combined measure of inorganic and organic coastal pollution, nutrient runoff and hypoxia, aquaculture activities and the presence of invasive species in the study area and represents an annual value of the impact (Coll et al., 2012). The fishing effort dataset was calculated from raw data provided by the General Secretariat of Fisheries of the Spanish Ministry of Agriculture, Food and Environment (MAPAMA) from the vessel monitoring systems (VMS) for the two seasons in 2013. Unprocessed VMS data do not indicate whether a vessel is fishing or not, so a speed filter was applied to raw data. Only records from 
vessels with fishing activity (i.e. speed up to 4 knots) (Martín et al., 2014) were taken into account, and these positions were plotted using QGIS software (QGIS Development Team, 2012) to represent the spatial distribution of fishing effort.

\begin{tabular}{|c|c|c|c|c|}
\hline Variable & Description & Units & Effects & Source \\
\hline Season & $\begin{array}{c}\text { Season when the sample was } \\
\text { collected }\end{array}$ & $\begin{array}{c}\text { winter, } \\
\text { summer }\end{array}$ & Random & ECOTRANS \\
\hline Depth & $\begin{array}{c}\text { Depth of the sampling location } \\
\text { metres }\end{array}$ & Random & ECOTRANS \\
\hline SST & $\begin{array}{c}\text { Sea surface temperature in the } \\
\text { sampling location }\end{array}$ & ${ }^{\circ} \mathrm{C}$ & Fixed & ECOTRANS \\
\hline SBT & $\begin{array}{c}\text { Sea bottom temperature in the } \\
\text { sampling location }\end{array}$ & ${ }^{\circ} \mathrm{C}$ & Fixed & ECOTRANS \\
\hline SSS & $\begin{array}{c}\text { Salinity in the sampling } \\
\text { location }\end{array}$ & PSS & Fixed & ECOTRANS \\
\hline Fluorescence & $\begin{array}{c}\text { Fluorescence in the sampling } \\
\text { location }\end{array}$ & $\mu \mathrm{g}$ Chl-1 $\mathrm{l}^{-1}$ & Fixed & ECOTRANS \\
\hline $\begin{array}{c}\text { Type of } \\
\text { substrate }\end{array}$ & $\begin{array}{c}\text { Substrate in the sampling } \\
\text { location }\end{array}$ & $\begin{array}{c}\text { fine mud, } \\
\text { sand, sandy } \\
\text { mud }\end{array}$ & Fixed & EMODnet \\
\hline Effort & $\begin{array}{c}\text { Fishing effort in the sampling } \\
\text { location }\end{array}$ & $\begin{array}{c}\mathrm{h} \cdot \mathrm{km}^{-2} \\
\text { from } 0(\mathrm{low}) \\
\text { to } 1(\mathrm{high})\end{array}$ & Fixed & $\begin{array}{c}\text { GSF of } \\
\text { MAPAMA }\end{array}$ \\
\hline $\begin{array}{c}\text { Coastal } \\
\text { impact }\end{array}$ & $\begin{array}{c}\text { Coastal impact in the sampling } \\
\text { location }\end{array}$ \\
\hline
\end{tabular}

GSF of MAPAMA: General Secretariat of Fisheries of the Spanish Ministry of Agriculture, Food and Environment

Table 1. Summary of variables included in Bayesian models as potential fixed-effects variables influencing the abundance, biomass and biodiversity of demersal assemblages.

\section{e) Species distribution modelling}

We used BSDMs, to estimate the effect of the explanatory variables (Table 1) on species abundance, biomass, Shannon index and richness dependency of the demersal community, fish, cephalopod and crustacean assemblages for each season (winter and summer). BSDMs implemented in this study were similar to General Linear Models applying different exponential probability distribution families (Gaussian, Gamma or Poisson) depending to the response variable. The BSDMs used in this study can be considered as a spatial extension of GLMs because the modeling process describes the variability in the response variable as a function of the explanatory variables, with the addition of a stochastic spatial effect, which models the residual spatial autocorrelation (Lindgren, 2012). The spatial effect is a numeric vector linking each observation to a spatial location, and thus it accounts for independent region-specific noise that cannot be explained by the available covariates (Muñoz et al., 2013). Specifically, we used a point-reference spatial model, that is highly suitable for situations (such as that of the present study) in which data are observed at continuous locations occurring within a defined spatial domain (geo-referenced data). Bayesian inference 
and predictions were obtained through the Integrated Nested Laplace Approximations (INLA) approach (Rue et al., 2009) and the package (http://www.r-inla.org/) implemented in R software (R Core Team, 2017).

Model selection was performed by beginning with all possible interaction terms, and based on three different measures: Deviance Information Criterion (DIC) (Spiegelhalter et al., 2002), Watanabe-Akaike information criterion (WAIC) (Watanabe, 2010), and Log-Conditional Predictive Ordinates (LCPO) (Roos and Held, 2011). Specifically, DIC and WAIC were used as a measure for goodness-of-fit, and the LCPO for predictive quality. The smaller the DIC, WAIC and LCPO values, the better the compromise between fit, parsimony and predictive quality. The best (and most parsimonious) model was ultimately chosen based on the compromise between low DIC, WAIC and LCPO values, containing only relevant predictors; i.e., those predictors with $95 \%$ credibility intervals not including zero. Therefore, the accuracy of the model was assessed through the log-conditional predictive ordinates (LCPO) (Roos and Held, 2011) which is a "leaveoneout" cross-validation index to assess the predictive power of the model (Pennino et al., 2019). (See detailed information about BSDMs and model selection procedure in Appendix 4 in supporting information).

\section{Results}

\section{a) Field estimates of abundance, biomass and biodiversity}

Regarding Kruskall-Wallis tests, results showed significant differences between abundance and biomass estimates of the demersal community between winter and summer (p-value $<0.05$ ) (Table 2), except for the biomass of cephalopods ( $\mathrm{p}$-value $=0.56$ ). Species richness and Shannon index showed significant differences between winter and summer as well ( $p$-value $<0.05$ ), except for the Shannon index of the total community ( $p$ value $=0.10$ ), of the fish assemblage ( $p$-value $=0.93)$, and for cephalopod richness ( $p$-value $=0.65)$ (Table 2). On the other hand, Welch tests showed significant differences ( $p$-value $<0.05$ ) in biomass between seasons for the fish assemblage and the entire demersal community and in abundance for crustaceans. Also, Welch test showed significant differences in species richness between seasons for the four groups (Table 2).

Table 2. Average, median, standard deviation (sd), minimum values (min) and maximum values (max) of observed abu $\left(\mathrm{kg} / \mathrm{km}^{2}\right)$, observed richness index $\left(\mathrm{n} / \mathrm{km}^{2}\right)$ and observed Shannon index of the demersal community and of fish, cephalop both seasons (winter and summer). $P$ values indicate the difference between seasons of all response variables for e. (Kruskal-Wallis: $K-W$ and Welch: W)

\begin{tabular}{|c|c|c|c|c|c|c|c|c|c|c|}
\hline & & \multicolumn{8}{|c|}{ Winter } & \multirow[t]{2}{*}{$\overline{P(W)}$} \\
\hline & & average & median & $\mathrm{sd}$ & $\min$ & $\max$ & average & median & $\mathrm{sd}$ & \\
\hline \multirow{4}{*}{ Total } & Abundance & $9,191.23$ & $\begin{array}{c}6,139.4 \\
0\end{array}$ & $11,010.77$ & $1,494.52$ & $5,7076.88$ & $36,332.50$ & $11,871.66$ & $115,286.52$ & $\begin{array}{c}2,763 . \\
2 \\
\end{array}$ \\
\hline & Biomass & 272.47 & 187.42 & 252.08 & 55.99 & $1,409.36$ & 650.14 & 428.76 & 912.40 & 54.68 \\
\hline & Richness & 28.73 & 29.00 & 6.87 & 11.00 & 41.00 & 35.07 & 35.00 & 6.49 & 22.00 \\
\hline & Shannon & 2.24 & 2.34 & 0.50 & 0.37 & 2.99 & 2.36 & 2.52 & 0.58 & 0.36 \\
\hline \multirow{4}{*}{ Fish } & Abundance & $5,153.95$ & $\begin{array}{c}2,900.8 \\
9\end{array}$ & $6,076.69$ & 696.03 & $3,0552.75$ & $31,566.75$ & $6,854.74$ & $11,5250.18$ & 764.1 \\
\hline & Biomass & 192.04 & 113.95 & 234.55 & 32.35 & $1,253.49$ & 536.21 & 276.54 & 844.62 & 44.69 \\
\hline & Richness & 17.22 & 18.00 & 4.63 & 7.00 & 26.00 & 21.49 & 21.00 & 4.58 & 13.00 \\
\hline & Shannon & 1.93 & 2.06 & 0.46 & 0.85 & 2.64 & 1.92 & 1.98 & 0.54 & 0.33 \\
\hline
\end{tabular}




\begin{tabular}{|c|c|c|c|c|c|c|c|c|c|c|}
\hline \multirow{4}{*}{ Cephalopod } & Abundance & $1,188.58$ & 933.32 & 877.83 & 60.41 & $4,180.31$ & $1,683.84$ & $1,399.30$ & $1,215.39$ & 100.7 \\
\hline & Biomass & 66.79 & 62.69 & 36.15 & 12.02 & 175.02 & 95.30 & 64.02 & 94.44 & 2.42 \\
\hline & Richness & 5.19 & 5.00 & 1.29 & 2.00 & 8.00 & 5.29 & 5.00 & 1.38 & 2.00 \\
\hline & Shannon & 0.96 & 0.95 & 0.34 & 0.29 & 1.68 & 1.10 & 1.09 & 0.25 & 0.24 \\
\hline \multirow{4}{*}{ Crustacean } & Abundance & $2,848.70$ & 565.39 & $9,156.25$ & 0.00 & 55434.06 & 3081.90 & $1,310.41$ & $5,170.13$ & 178.3 \\
\hline & Biomass & 13.56 & 4.62 & 23.76 & 0.00 & 118.99 & 18.58 & 9.76 & 25.56 & 1.20 \\
\hline & Richness & 6.32 & 6.00 & 3.84 & 0.00 & 19.00 & 8.29 & 8.00 & 3.35 & 3.00 \\
\hline & Shannon & 1.05 & 0.98 & 0.61 & 0.00 & 2.37 & 1.32 & 1.32 & 0.50 & 0.09 \\
\hline
\end{tabular}

\section{b) Predicted abundance, biomass and biodiversity distributions of the demersal community}

Season, spatial effect and SST were selected as relevant predictors of whole community abundance, biomass, and biodiversity (Table 3 and Table 4, and Table S3.2). Abundance, biomass, species richness and Shannon index showed a positive correlation with the SST (Table 4). So, areas with higher SST were also those with higher values of the biological response variables (Table 3 and Table 4, and Table S3.2).

Results for the predicted distribution of abundance in winter showed evidence for higher values in the central part of the study area (Fig. 2a). Results for the predicted distribution of abundance in summer showed higher values for the central and southern parts of the study area, mainly located in the continental shelf (Fig. 2b). Biomass distribution predicted patterns that were quite similar to the abundance distribution patterns (Fig. $2 \mathrm{c}$ and $2 \mathrm{~d}$ ). The predicted distribution of the richness index differed between seasons (Fig. $2 \mathrm{~g}$ and $2 \mathrm{~h}$ ). Higher values were seen in the central part of the study area, whereas in winter higher values were more diffused in the central and southern part. These patterns showed similarities to the distribution of biomass (Fig. 2c and 2d). The distributions predicted by the Shannon index (Fig. 2e and 2f) showed similar patterns between seasons: they were characterised by lower values in the surroundings of the Ebro River Delta and the southwestern part of the study area. 

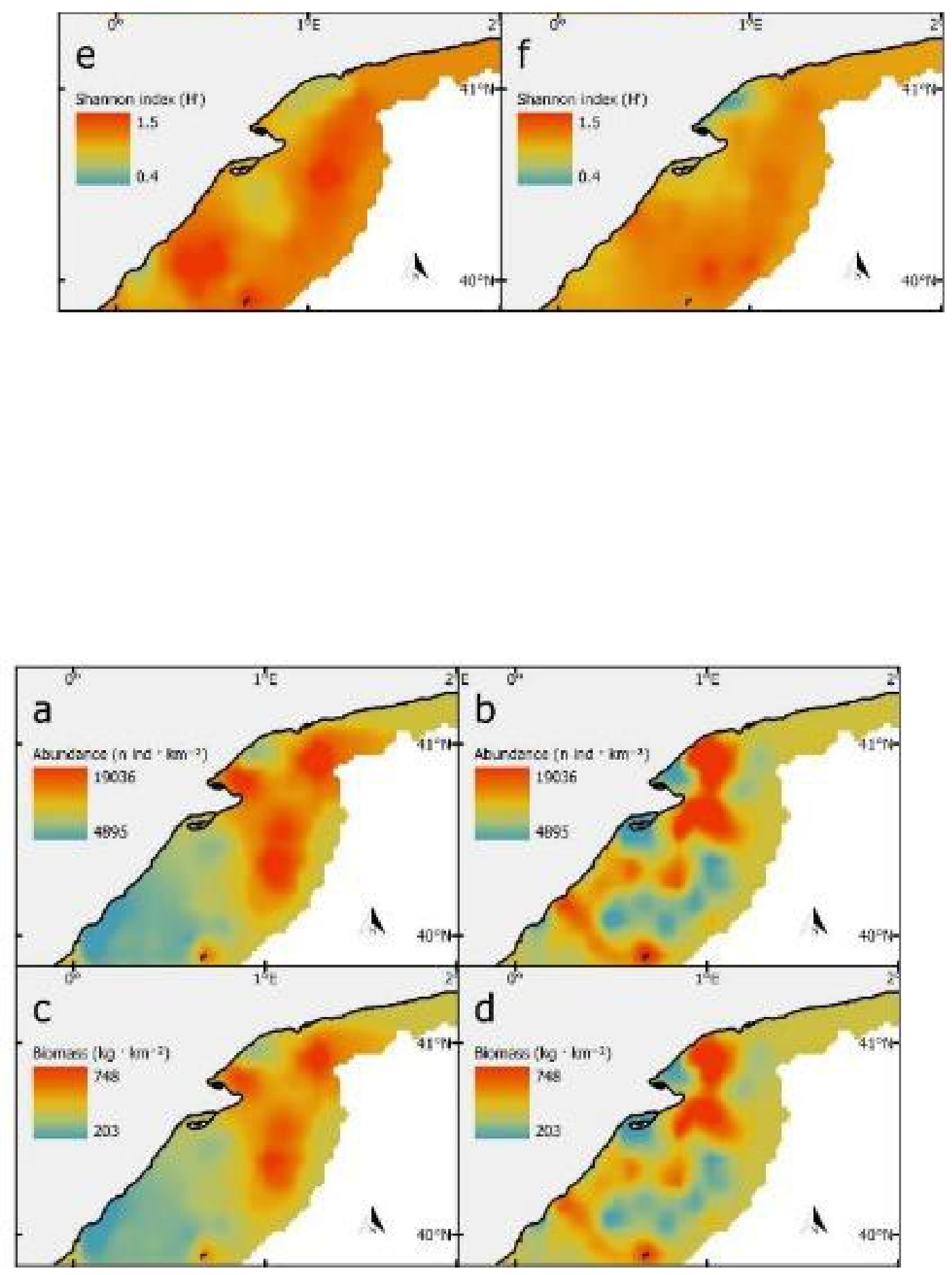


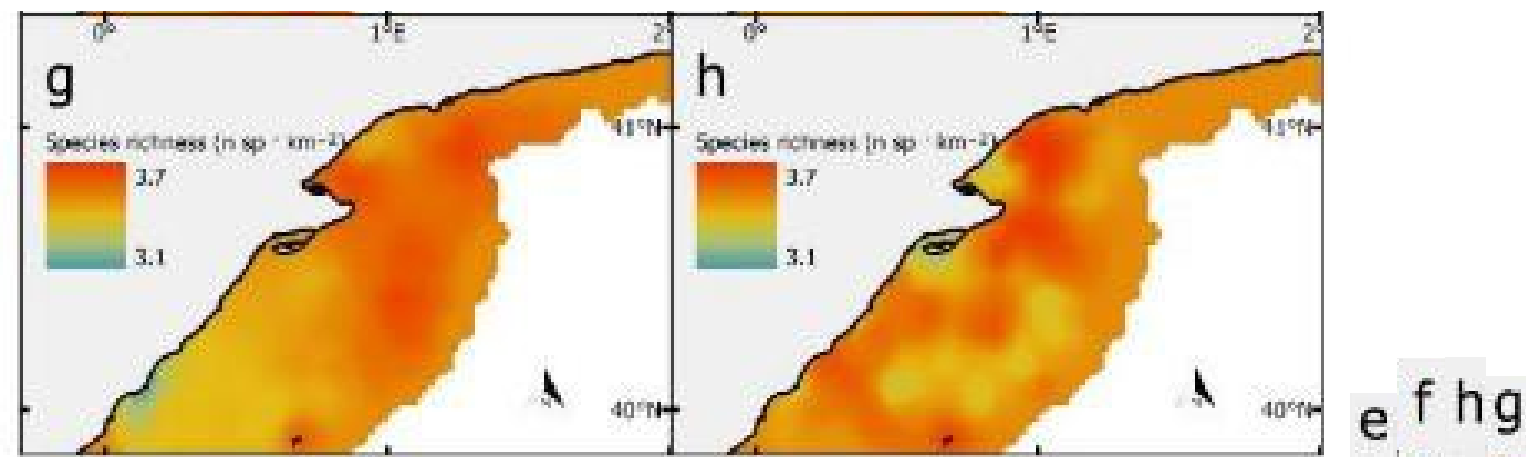

Figure 2. Total demersal assemblage distribution of the posterior means of ( $a, b)$ abundance, $(c, d)$ biomass, $(e, f)$ species richness and $(g, h)$ Shannon index (left) winter and (right) summer, respectively (refer to Figure 1 for further details on the study area).

\section{c) Predicted abundance, biomass and biodiversity distributions of fish}

Fish abundance, biomass and diversity models indicated season, spatial effect and SST as best predictors, with the exception of the Shannon index which indicated fluorescence instead of SST (Table 3 and Table 4, and Table S3.2). 
SST showed a positive relationship with the abundance, biomass and the richness index of fish group (Table 4). The fluorescence showed a negative relationship with the Shannon index of the fish group (Table 4).

The predicted distribution of fish abundance showed higher values in the central part of the study area during winter, and showed an extension from the continental shelf to the upper slope (Fig. 3a). In summer, higher values appeared on the central and southern part of the study area, and were located in the continental shelf (Fig. 3b). Distribution patterns predicted by biomass were opposite to abundance patterns during both seasons (Fig. 3c and 3d). The highest predicted richness in winter was located in the central part of the study area, while in summer it was in the central and southern coastal region (Fig. $3 \mathrm{~g}$ and $3 \mathrm{~h}$ ). The Shannon index showed similar predicted distributions between winter and summer (Fig. 3e and 3f), with higher values in the southern part of the study area and in the central part of the study area close to the upper slope. 

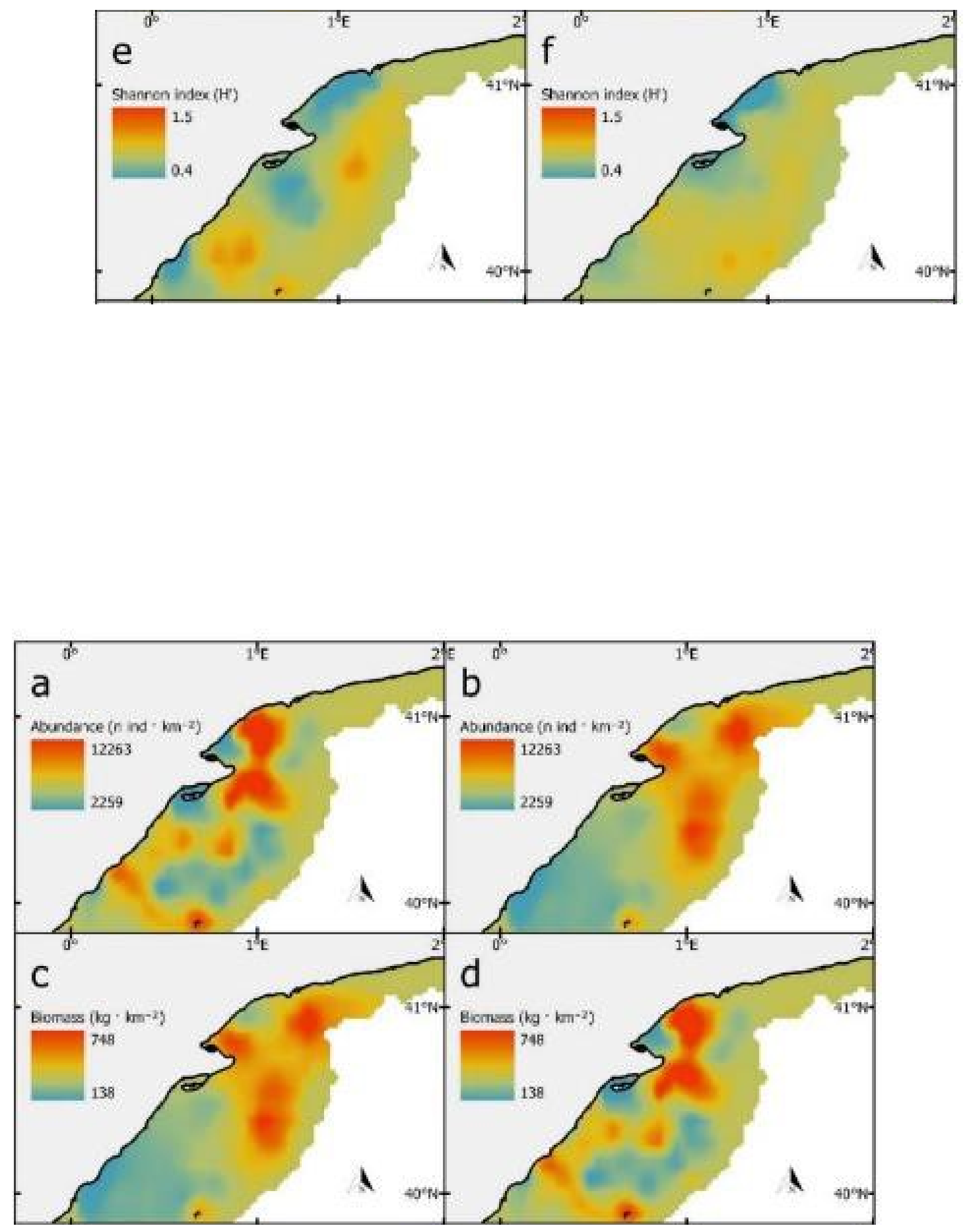

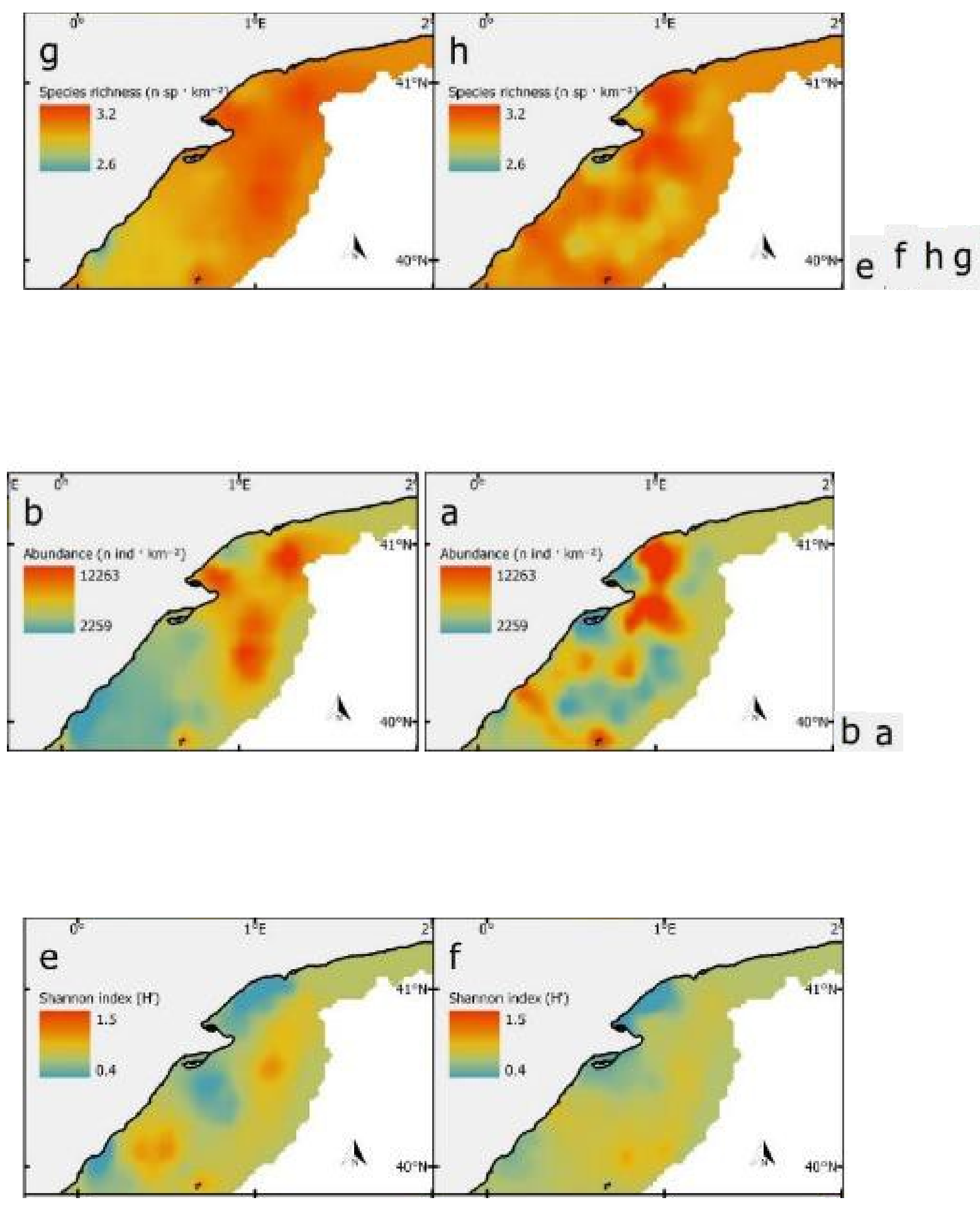

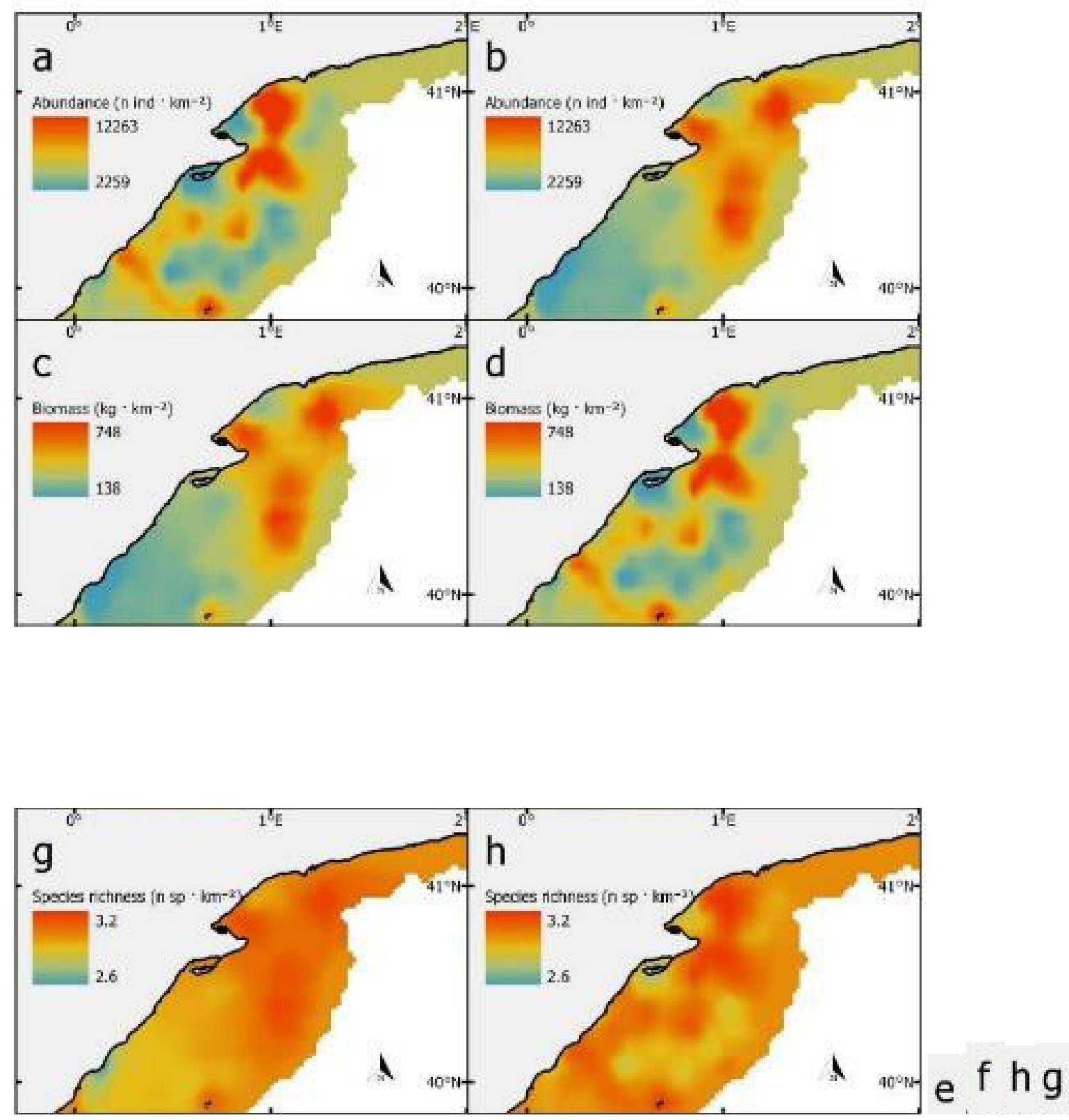
Figure 3. Fish assemblage distribution of the posterior means of $(a, b)$ abundance, $(c, d)$ biomass, $(e, f)$ species richness and $(g, h)$ Shannon index for (left) winter and (right) summer, respectively (refer to Figure 1 for further details on the study area).

\section{d) Predicted abundance, biomass and biodiversity distributions of cephalopods}

For the cephalopod assemblage, season, spatial effect and SSS (abundance and biomass) or SST (biodiversity), were selected as relevant predictors for all dependent variables (Table 3 and Table 4, and Table S3.2). SSS showed a negative relationship with cephalopod abundance and biomass, i.e., areas with higher biomass were also those with lower SSS (Table 4). SST showed a positive relationship with the species richness and the Shannon index of the cephalopod group. 

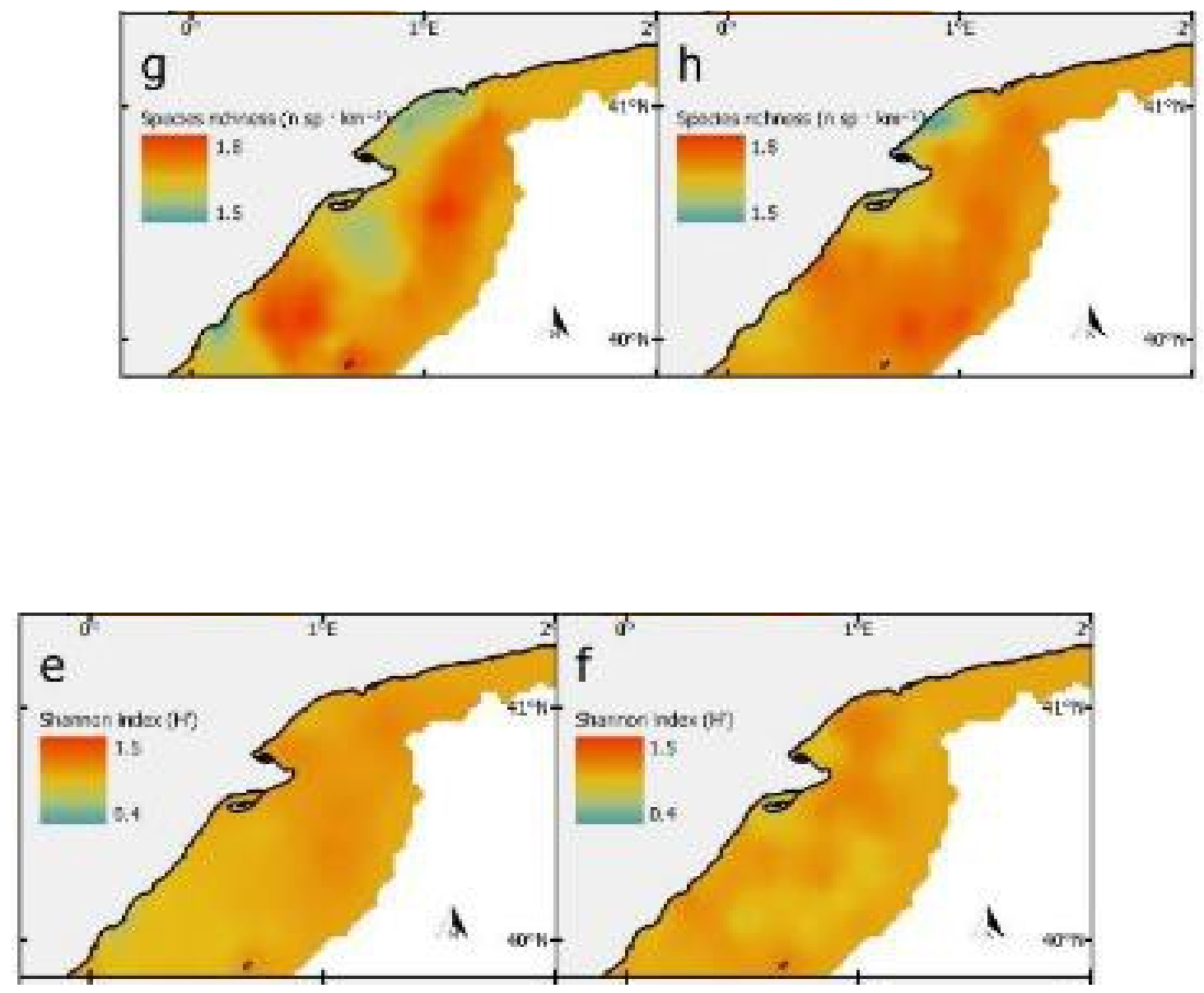


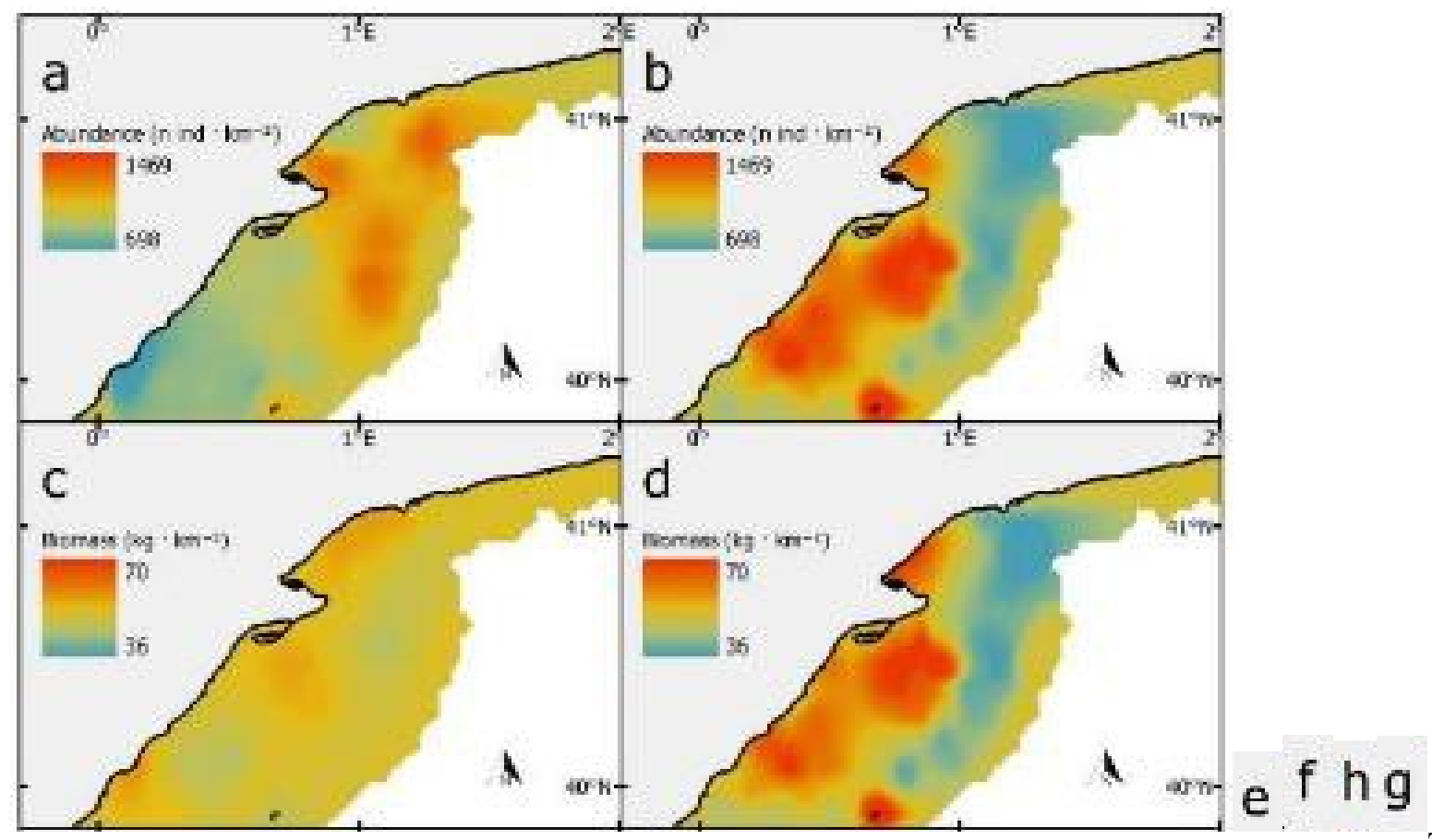

The

predicted distribution of cephalopod abundance revealed practically opposite patterns between seasons: higher values were located in the northern-central upper slope in winter, while in the summer high abundance values were in the southern-central continental shelf area (Fig. 4a and 4b). Distribution patterns of cephalopods predicted by biomass were more homogenous in winter than in summer, although it was possible to distinguish maximum values of biomass around the Ebro River Delta in winter (Fig. 4c and 4d). The biomass in the summer was distributed similarly along the study area while in the winter there was a concentration in coastal areas. Predicted distributions of cephalopod richness (Fig. 4g and 4h) showed similar patterns in both seasons, with higher values in the central upper slope and in the southern part of the study area. The predicted distribution of the Shannon index for cephalopods showed homogenous patterns (Fig. $4 \mathrm{e}$ and $4 \mathrm{f}$ ), although higher values were located in the central part of the study area during winter while in summer they were closer to the shoreline.

Figure 4. Cephalopod assemblage distribution of the posterior means of $(a, b)$ abundance, $(c, d)$ biomass, $(e$, f) species richness and $(g, h)$ Shannon index for (left) winter and (right) summer, respectively (refer to Figure 1 for further details on the study area).

\section{e) Predicted abundance, biomass and biodiversity distributions of crustaceans}

For crustacean models, season, spatial effect and depth were selected as relevant predictors in all the models. In addition, fishing effort was selected as a relevant variable in the case of abundance and biomass, while SBT was selected when predicting biodiversity patterns (Table 3 and Table 4, and Table S3.2). SST, depth and fishing effort showed a positive relationship with crustacean abundance and biomass (Table 4). 
SBT and depth showed a positive relationship with the species richness and the Shannon index for the crustacean group.
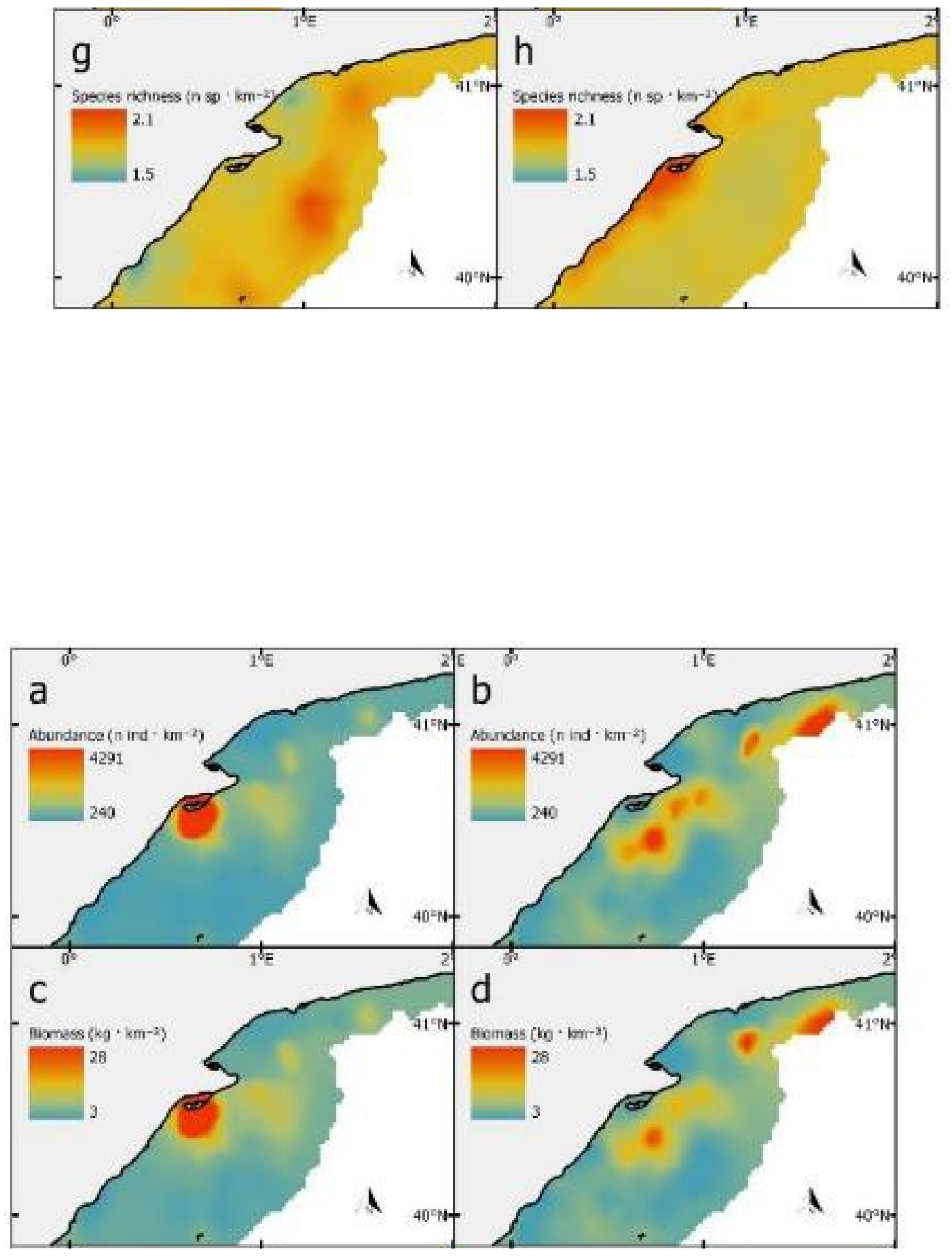

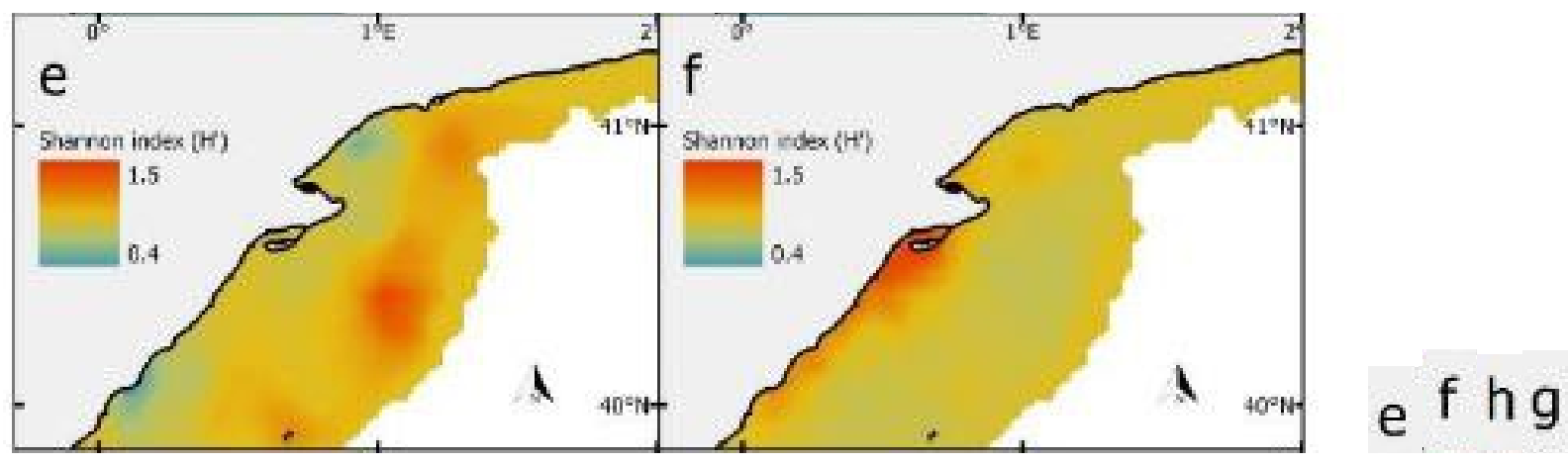

Dist

ribution patterns predicted by abundance were different between seasons (Fig. 5a and 5b). In winter, the hotspot of abundance was located in the south of the coastal area of the Ebro Delta, while in the summer two regions were highlighted: one in the upper slope in the north of the study area, and the other in the continental shelf in the central part of the study area. Distribution patterns predicted by biomass (Fig. $5 \mathrm{c}$ and 5f) were very similar to those obtained for abundance. The predicted distributions of the species richness showed differences between the two seasons: higher values of biodiversity in winter were located closer to the upper slope, while in the summer they were higher on the shoreline of the southern part (Fig. 5e and 5f). Distributions predicted by the Shannon index for the crustacean assemblage showed very similar patterns to the species richness (Fig. $5 \mathrm{~g}$ and $5 \mathrm{~h}$ ).

Figure 5. Crustacean assemblage distribution of the posterior means of (a, b) abundance, $(c, d)$ biomass, (e, f) species richness and $(g, h)$ Shannon index for (left) winter and (right) summer, respectively (refer to

Figure 1 for further details on the study area).

\begin{tabular}{|c|c|c|c|c|c|}
\hline & & Model & DIC & WAIC & LCPO \\
\hline \multirow{4}{*}{ Total } & Abundance & $\mathrm{b} 0+\mathrm{W}+\mathrm{S}+\mathrm{SST}$ & 188.12 & 190.46 & 1.19 \\
\hline & Biomass & $\mathrm{b} 0+\mathrm{W}+\mathrm{S}+\mathrm{SST}$ & 164.3 & 166.45 & 1.03 \\
\hline & Richness & $\mathrm{b} 0+\mathrm{W}+\mathrm{S}+\mathrm{SST}$ & 544.69 & 546.92 & 3.34 \\
\hline & Shannon & $\mathrm{b} 0+\mathrm{W}+\mathrm{S}+\mathrm{SST}$ & 181.14 & 185.18 & 1.12 \\
\hline \multirow{4}{*}{ Fish } & Abundance & $\mathrm{b} 0+\mathrm{W}+\mathrm{S}+\mathrm{SST}$ & 188.35 & 190.06 & 1.18 \\
\hline & Biomass & $\mathrm{b} 0+\mathrm{W}+\mathrm{S}+\mathrm{SST}$ & 167.12 & 168.47 & 1.03 \\
\hline & Richness & $\mathrm{b} 0+\mathrm{W}+\mathrm{S}+\mathrm{SST}$ & 474.45 & 475.42 & 2.95 \\
\hline & Shannon & b0+W+S+Fluorescence & 125.62 & 127.83 & 0.79 \\
\hline \multirow{4}{*}{ Cephalopo } & Abundance & $\mathrm{b} 0+\mathrm{W}+\mathrm{S}+\mathrm{SSS}$ & 174.71 & 179.91 & 1.14 \\
\hline & Biomass & $\mathrm{b} 0+\mathrm{W}+\mathrm{S}+\mathrm{SSS}$ & 198.28 & 201.81 & 1.24 \\
\hline & Richness & $\mathrm{b} 0+\mathrm{W}+\mathrm{S}+\mathrm{SST}$ & 320.26 & 318.07 & 1.93 \\
\hline & Shannon & $\mathrm{b} 0+\mathrm{W}+\mathrm{S}+\mathrm{SST}$ & 36.97 & 37.6 & 0.23 \\
\hline \multirow{4}{*}{ Crustacean } & Abundance & b0+W+S+SST+Depth+Effort & 250.14 & 253.12 & 1.58 \\
\hline & Biomass & b0+W+S+SST+Depth+Effort & 221.09 & 22.06 & 1.35 \\
\hline & Richness & b0+W+S+SBT+Depth & 389.52 & 387.65 & 2.36 \\
\hline & Shannon & $\mathrm{b} 0+\mathrm{W}+\mathrm{S}+\mathrm{SBT}+\mathrm{Depth}$ & 124.87 & 124.96 & 0.76 \\
\hline
\end{tabular}


Table 3. Final selected models for every predicted variable of total demersal community, fishes, cephalopods and crustaceans. Statistics acronyms are: WAIC $=$ Watanabe-Akaike Information Criterion; $L C P O=$ LogConditional Predictive Ordinates. Predictors' acronyms are: SST = Sea Surface Temperature; SBT = Sea Bottom Temperature; SSS = Sea Surface Salinity; Impact = Coastal impact; Effort = Fishing effort; $S=$ season; $W=$ spatial random effect; $b 0=$ Intercept. Complementary results are provided in Appendix 3 Table S3.2.

\begin{tabular}{|c|c|c|c|c|c|c|c|}
\hline \multicolumn{2}{|c|}{ Model } & Predictor & mean & $\mathrm{sd}$ & $\mathrm{Q}_{0.025}$ & $\mathrm{Q}_{0.5}$ & $\mathrm{Q}_{0.975}$ \\
\hline \multirow{8}{*}{ Total } & \multirow{2}{*}{ Abundance } & Intercept & 9.11 & 0.65 & 7.71 & 9.11 & 10.52 \\
\hline & & SST & 0.24 & 0.08 & 0.05 & 0.24 & 0.34 \\
\hline & \multirow{2}{*}{ Biomass } & Intercept & 5.81 & 0.66 & 4.41 & 5.80 & 7.25 \\
\hline & & SST & 0.37 & 0.07 & 0.24 & 0.37 & 0.51 \\
\hline & \multirow{2}{*}{ Richness } & Intercept & 3.47 & 0.11 & 3.24 & 3.47 & 3.70 \\
\hline & & SST & 0.23 & 0.02 & 0.03 & 0.23 & 0.45 \\
\hline & \multirow{2}{*}{ Shannon } & Intercept & 0.84 & 0.12 & 0.68 & 0.84 & 1.01 \\
\hline & & SST & 0.07 & 0.04 & 0.01 & 0.07 & 0.16 \\
\hline \multirow{8}{*}{ Fish } & \multirow{2}{*}{ Abundance } & Intercept & 8.51 & 2.84 & 2.39 & 8.56 & 14.36 \\
\hline & & SST & 0.49 & 0.08 & 0.33 & 0.49 & 0.65 \\
\hline & \multirow{2}{*}{ Biomass } & Intercept & 1.70 & 0.82 & 0.19 & 1.70 & 3.21 \\
\hline & & SST & 0.50 & 0.02 & 0.36 & 0.50 & 0.65 \\
\hline & \multirow{2}{*}{ Richness } & Intercept & 2.97 & 1.18 & 0.64 & 2.97 & 5.28 \\
\hline & & SST & 0.09 & 0.03 & 0.04 & 0.09 & 0.14 \\
\hline & \multirow{2}{*}{ Shannon } & Intercept & 0.64 & 1.45 & -1.95 & 0.64 & 3.23 \\
\hline & & Fluorescence & -0.18 & 0.03 & -0.24 & -0.18 & -0.12 \\
\hline \multirow{8}{*}{ Cephalopod } & \multirow{2}{*}{ Abundance } & Intercept & 6.92 & 0.30 & 6.28 & 6.93 & 7.53 \\
\hline & & SSS & -0.20 & 0.08 & -0.36 & -0.20 & -0.06 \\
\hline & \multirow{2}{*}{ Biomass } & Intercept & 3.90 & 2.74 & -1.64 & 3.92 & 9.30 \\
\hline & & SSS & -0.20 & 0.10 & -0.40 & -0.20 & -0.01 \\
\hline & \multirow{2}{*}{ Richness } & Intercept & 1.65 & 0.14 & 1.31 & 1.65 & 1.97 \\
\hline & & SST & 0.08 & 0.05 & 0.03 & 0.08 & 0.14 \\
\hline & \multirow{2}{*}{ Shannon } & Intercept & 1.03 & 0.99 & -0.24 & 1.02 & 2.31 \\
\hline & & SST & 0.07 & 0.03 & 0.01 & 0.07 & 0.16 \\
\hline \multirow{14}{*}{ Crustacean } & \multirow{4}{*}{ Abundance } & Intercept & 6.18 & 3.81 & -1.41 & 6.29 & 13.24 \\
\hline & & SST & 0.43 & 0.13 & 0.12 & 0.43 & 0.68 \\
\hline & & Depth & 0.01 & 0.00 & 0.00 & 0.01 & 0.09 \\
\hline & & Effort & 0.63 & 0.13 & 0.38 & 0.63 & 0.88 \\
\hline & \multirow{4}{*}{ Biomass } & Intercept & 1.68 & 3.00 & -4.69 & 1.69 & 7.96 \\
\hline & & $\mathrm{SST}^{-}$ & 0.26 & 0.10 & 0.09 & 0.26 & 0.46 \\
\hline & & Depth & 0.05 & 0.00 & 0.02 & 0.01 & 0.08 \\
\hline & & Effort & 0.47 & 0.10 & 0.27 & 0.48 & 0.68 \\
\hline & \multirow{3}{*}{ Richness } & Intercept & 1.37 & 3.99 & -6.90 & 1.39 & 9.47 \\
\hline & & SBT & 0.08 & 0.04 & 0.00 & 0.08 & 0.17 \\
\hline & & Depth & 0.04 & 0.00 & 0.00 & 0.00 & 0.06 \\
\hline & \multirow{3}{*}{ Shannon } & Intercept & 0.90 & 1.13 & -1.49 & 0.91 & 3.23 \\
\hline & & SBT & 0.15 & 0.06 & 0.04 & 0.15 & 0.27 \\
\hline & & Depth & 0.02 & 0.00 & 0.00 & 0.02 & 0.04 \\
\hline
\end{tabular}

Table 4. Numerical summary of the posterior distribution of the fixed effects for the best model of every predicted variable of total demersal community, fishes, cephalopods and crustaceans. This summary contains the mean, the standard deviation (SD), the median and a 95\% credible interval, which is a central 21 
interval containing $95 \%$ of the probability under the posterior distribution. Complementary results are provided in Appendix 3 Table S3.2.

\section{f) Common patterns of predicted variables}

Seasonality and spatial effect were selected as relevant independent variables for all statistical models. In addition, almost all selected models included temperature (SST or SBT) as a relevant predictor, except for the Shannon index of fish where fluorescence was selected instead, and abundance and biomass of the cephalopod assemblage where SSS was selected. All final crustacean models selected depth as a relevant variable, and fishing effort was included for predictions of crustacean abundance and biomass.

Taking into account the predicted distributions resulting from the BSDMs, abundance and biomass obtained similar patterns in both seasons for the four groups. Therefore, the Ebro Delta surroundings and the upper-slope area were highlighted as areas of higher concentrations of abundance and biomass of demersal organisms in winter ("winter hotspots"). In the summer, concentration areas were more spread out along the continental shelf, with a concentration area around the Columbretes islands (a "summer hotspot"), with the exception of crustaceans, which showed a reverse pattern with concentrations closer to the coast in winter.

\section{Discussion}

Using seasonal scientific survey (fishery-independent) data, we investigated the spatial patterns of abundance, biomass, and biodiversity of a NW Mediterranean demersal community and their relationship with environmental, physical and anthropogenic factors. Overall, our findings highlighted the importance of two main variables to predict spatial patterns of abundance and biomass: the season and spatial effects.

A previous study analysed the seasonality effect in the NW Mediterranean Sea (Gaertner, 2000) and found a seasonal influence in only a few fish species, including Deltentosteus quadrimaculatus and Mullus barbatus. On the contrary, our results revealed that seasonality strongly affected the distributions of demersal species assemblages (including fish, cephalopods and crustaceans). Indeed, most of the data showed differences between summer and winter. Estimates of abundance and biomass showed significant differences between seasons (except for cephalopod biomass), highlighting a change in density of demersal fauna. Considering estimates of biodiversity, species richness and Shannon index showed significant seasonal patterns as well (except for total Shannon diversity, fish Shannon diversity and cephalopod species richness). Therefore, intra-annual seasonality is key to the dynamics of marine resources in the NW Mediterranean Sea, and should be considered in additional studies, although obtaining information at the seasonal level is problematic in many areas (Albo-Puigserver et al., 2016). The seasonal change described in our study is driven by environmental parameters (mainly SST), which showed two clearly different states in winter and summer. Recent studies (Navarro et al., 2015; Coll et al., 2016) identified annual temperature as important variable to describe the spatial patterns of the species in the same study area, although they did not include the seasonal pattern. In our study, the sea surface temperature variable was positively related to several 
biological variables. Thus, areas with high sea surface temperature were also areas with high abundance, biomass and biodiversity. In fact, the increase in sea temperature in summer may cause an increase in abundance and biomass as this is when the highest growth rates occur as well as reproduction and feeding migration events (Morales-Nin and Moranta, 2004). Other studies have shown similar patterns in other Mediterranean Sea areas (Kallianiotis et al., 2000). Our results are consistent with global studies that positively linked biodiversity to sea surface temperature (Tittensor et al., 2010; Costello and Chaudhary, 2017), highlighting that warmer areas present higher biodiversity. Tittensor et al. (2010) showed a global spatial positive correlation between biodiversity and the sea surface temperature (SST) for coastal marine groups. In the NW Mediterranean Sea, the SST is considered an important variable shaping demersal community, and it is due to several reasons such us availability of food (Olivar et al., 2010). Therefore, temperature is a key environmental variable, controlling the rates of physiological processes such as metabolism and growth (Damalas et al., 2016). Other studies described seasonal distribution patterns for some species that could be related with seasonal changes on temperature (e.g. Maynou et al. 2003b). In our case, the relevant temperature for crustaceans was bottom temperature (SBT), probably because crustaceans live in close relationship with the seabed. Since global and regional projections of climate change predict a continuous increase in sea temperature (both in the surface and at the bottom) in the Mediterranean Sea (Calvo et al., 2011), it will be essential to take into account this variable in species distribution projections as it will surely play a key role in future climate change scenarios.

In our models, seasonal importance was also evident in the predictive distribution maps. The spatial predictions of abundance and biomass showed a general migration pattern from upper-slope in winter to the continental shelf in summer, which was determined as a recruitment and spawning processes for several species in other Mediterranean areas (Colloca et al., 2015). Therefore, abundance and biomass spatial predictions showed similar spatial patterns which demonstrated their spatial correlation. Also, they highlighted the surrounding of Ebro River Delta as a hotspot for the demersal fish community. This area is well known for its permanent local upwelling caused by the penetration of northern slope water masses (Font et al., 1990) and consequently its nutrient-enrichment which support high productive food-webs, in addition to the proximity of this area to the river discharges of the Ebro river, which have been shown to be linked to increase in catches (Lloret et al., 2001). These migrations between seasons can be related to spawning, nursing or feeding events by demersal species in the study area, as already described for some species such as the European hake (Merluccius merluccius) (Maynou et al., 2003), blue whiting (Micromesistius poutassou) (Abad et al., 2007) and anglerfish (Lophius piscatorius) (Demestre et al., 2000).

In addition, predicted abundance and biomass distribution for cephalopods showed a seasonal migration from the northern part in winter to the southern part in the summer, probably due to spawning aggregations in space and/or time described previously for some cephalopod species (Puerta et al., 2016), such as shortfin squid (Illex coindetti), horned octopus (Eledone cirrhosa) and common octopus (Octopus vulgaris). High abundance and biomass of cephalopods were located in areas with low abundance and biomass of fishes. This pattern could be related to a predation release process. Previous study described trophic impacts due to 
changes in species abundance and highlighted the removal of high trophic level organisms due to overfishing (Coll et al., 2008).

In addition, there is also seasonality in crustacean distribution: the main migration event that we observed was from coastal to deeper waters from winter to summer (thus, a pattern that is contrary to that observed for fish and cephalopods). This seasonal migration of crustaceans is mainly due to species-specific patterns in each season. For example, in winter the highest abundance and biomass is located in the area surrounding the Ebro River Delta due to the high density of mantis shrimp (Squilla mantis) (Abelló and Sardá, 1989), while summer is characterised by the dispersal of mantis shrimp adults (Maynou et al., 2004). Moreover, there are different seasonal crustacean migration patterns such as the case of blue-leg swimcrab (Liocarcinus depurator). This decapod migrates to deeper areas in summer due to hydrographic and sediment resuspension processes, which are connected to feeding behaviour (Abelló et al., 1988).

Three other environmental predictive variables were selected in our final models for some specific cases: salinity, fluorescence and depth. Regarding fluorescence, although Costello and Chaudhary (2017) described a positive correlation between primary production and biodiversity, in our case this relationship was negative for fishes (Table 4). This contradiction is due to the high values of primary production located close to the Ebro River Delta, and the fact that the Shannon index is calculated with fish abundance. Fish abundance is driven by the positive correlations with spatial effects (or depth) and the lower fish abundance areas in the surroundings of the Ebro River Delta have lower values of Shannon biodiversity. Species richness was positively correlated with SST, and thus warmer temperatures supported higher fish species richness. This correlation can be explained because warmer temperatures cause an increase in demand for food and consequently increased competition and predator-prey interactions. Thus, we could find areas of higher diversification (Tittensor et al., 2010; Costello and Chaudhary, 2017).

The importance of depth for abundance and biomass in different Mediterranean areas has previously been described (Bellido et al., 2008; Coll et al., 2010; Pennino et al., 2013; Navarro et al., 2015). In our study, depth was important in terms of biodiversity, as highlighted in previous studies (Silveira Simão, 2013; Navarro et al., 2015). However, depth was not relevant in most of the final models, unlike spatial effect. This is probably because the same part of the spatial variability of the data explained by depth was already explained by spatial effect (Navarro et al., 2015). The spatial effect used in BSDMs represents the intrinsic spatial variability of the data that could be due to several spatial processes that are not taken into account in the models, such as biological processes (competition, reproduction, directed migrations, etc.) (Carroll et al., 2010). Consequently, the spatial patterns highlighted by the spatial predicted maps could be the result of a combination of factors, such as geographic location and depth, but also other biological processes. It could also be that the studies that highlighted depth as a relevant factor for the demersal community distributions were based on annual data and that when seasonal environmental variables were included in the analyses, static features such as depth, slope and type of seabed lost importance.

Finally, fishing effort was positively selected only in crustacean models. This may indicate the capacity of fishing to reduce predators and competitors and thus benefit smaller organisms like crustaceans (Coll et 
al., 2008). This process, which is also known as trophic cascade, can affect species differently (Ward and Myers, 2005). Trophic cascades have been previously documented in the Mediterranean Sea (Pinnegar et al., 2000). On the contrary, (Navarro et al., 2015) found that fishing activity showed a negative effect on crustacean assemblage, probably because fishing effort can have a spatial effect depending on the area. These results require further investigation.

This research represents a pilot study, which aimed to investigate whether seasonality is an important component driving the spatial distribution of demersal species (fish, cephalopods and crustaceans) in the northwestern Mediterranean Sea. It is well known that environment conditions affect the dynamics of demersal marine communities (Moore et al., 2009), and in our study area sea-surface temperature is the main environmental variable that changes between seasons (winter and summer) (Salat et al., 2002b). In fact, our results revealed that seasonal patterns in the spatial distribution of the different demersal organism groups during the sampling year 2013 were mainly driven by sea-surface temperature, and similar patterns of temperature values are likely to be expected since environmental variables in 2013 are representative and recurrent for both seasons each year according to observations (see Figure 1b). However, in the present study we only examined two seasons of one year due to data availability, therefore further studies are needed to verify the existence of an annually recurrent seasonal effect (Steel et al., 2013). When dealing with data-poor situations like the one presented in this study, Bayesian models can provide satisfactory results (Fonseca et al., 2017). Since seasonal monitoring programs are scarce in the marine environment, and are mainly absent from the Mediterranean Sea, this study provides evidence on the necessity to perform additional scientific surveys along the year (such as in the MEDITS program in the Mediterranean Sea, which is carried out in spring (Bertrand et al., 2002b). Although extensive sea surveys are highly expensive, a program of semester (or ideally quarterly) local-scale surveys could be more affordable to confirm seasonal patterns of demersal marine species.

Overall, our study provides evidence of the importance of seasonal patterns in marine communities of fish, cephalopods and crustaceans from the NW Mediterranean Sea and highlights the need to expand current monitoring schemes to include seasonality. Models taking into account seasonal biotic and abiotic explanatory variables could be an interesting tool for the accurate mapping of the study area (Mendoza et al., 2014; Granger et al., 2015). In general, our results may be important to inform policy processes aimed at spatially designing management measures such as seasonal fishing restrictions to protect specific aggregations of species during reproduction or feeding, or to adapt local marine protected areas (MPAs) to seasonal processes (Mendoza et al., 2014). Our results showed a "winter hotspot" with high abundance, biomass and biodiversity of the demersal community around the Ebro River Delta and in the "upper slope". The first region is known to be an important productive area that can be a preferential habitat for many marine species (Coll et al., 2016). The upper slope may show higher concentrations of biomass abundance due to this area is further away from the coast and, in winter, a higher frequency of bad weather days may prevent fishing operations from reaching the area. In addition, the waters surrounding the Columbretes Islands showed high values of abundance, biomass and biodiversity during summer and could be a "summer hotspot". These islands have been a MPA since 1989, and thus provide a stable, high quality ecosystem for 25 
populations that live around the islands and could be exporting recruits to adjacent areas (Goñi et al., 2006). Due to the ecological role of the Columbretes Islands in summer, legal compliance and effective surveillance during this season may be key to ensuring the conservation benefits of this MPA. Similar results were found by Mendoza et al. (2014) regarding the demersal fishery in the vicinity of the Cape of Palos Marine Reserve (southern Spain, western Mediterranean Sea).

\section{References}

Abad, E., Preciado, I., Serrano, A., and Baro, J. 2007. Demersal and epibenthic assemblages of trawlable grounds in the northern Alboran Sea (western Mediterranean). Scientia Marina, 71: 513-524.

Abelló, P., Valladares, F. J., and Castellón, A. 1988. Analysis of the structure of decapod crustacean assemblages off the Catalan coast (North-West Mediterranean). Marine Biology, 98: 39-49.

Abelló, P., and Sardá, F. 1989. Some observations on the biology and fishery of Squilla mantis L. in the Catalan area (NW Mediterranean). Biology of stomatopods: 229-239.

Abelló, P., Carbonell, A., and Torres, P. 2002. Biogeography of epibenthic crustaceans on the shelf and upper slope off the Iberian Peninsula Mediterranean coasts: implications for the establishment of natural management areas. Scientia Marina, 66: 183-198.

Agostini, V. N., and Bakun, A. 2002. Ocean triads' in the Mediterranean Sea: physical mechanisms potentially structuring reproductive habitat suitability (with example application to European anchovy, Engraulis encrasicolus). Fisheries Oceanography, 11: 129-142.

Albo-Puigserver, M., Navarro, J., Coll, M., Layman, C. A., and Palomera, I. 2016. Trophic structure of pelagic species in the northwestern Mediterranean Sea. Journal of Sea Research, 117: 27-35.

Armstrong, C. W., Foley, N. S., Tinch, R., and van den Hove, S. 2012. Services from the deep: Steps towards valuation of deep sea goods and services. Ecosystem Services, 2: 2-13.

Bellido, J. M., Brown, A. M., Valavanis, V. D., Giráldez, A., Pierce, G. J., Iglesias, M., and Palialexis, A. 2008. Identifying essential fish habitat for small pelagic species in Spanish Mediterranean waters. Hydrobiologia, 612: 171.

Bertrand, J. A., Relini, L. O., Papaconstantinou, C., Jukic-Peladic, S., Souplet, A., de Sola, L. G., Piccinetti, C., et al. 2002a. Mediterranean marine demersal resources: the Medits international trawl survey (1994-1999) Sci. Mar. 66 (Suppl. 2): 2002. Sci. Mar, 66: 103-124.

Bertrand, J. A., de Sola, L. G., Papaconstantinou, C., Relini, G., and Souplet, A. 2002b. The general specifications of the MEDITS surveys. Scientia marina, 66: 9-17.

Bianchi, C. N., and Morri, C. 2000. Marine Biodiversity of the Mediterranean Sea: Situation, Problems and Prospects for Future Research. Marine Pollution Bulletin, 40: 367-376.

Bosc, E., Bricaud, A., and Antoine, D. 2004. Seasonal and interannual variability in algal biomass and primary production in the Mediterranean Sea, as derived from 4 years of SeaWiFS observations. Global Biogeochemical Cycles, 18. 
Calvo, E., Simó, R., Coma, R., Ribes, M., Pascual, J., Sabatés, A., Gili, J. M., et al. 2011. Effects of climate change on Mediterranean marine ecosystems:: the case of the Catalan Sea. Climate Research, 50: 129.

Canals, M., Danovaro, R., Heussner, S., Lykousis, V., Puig, P., Trincardi, F., Calafat, A. M., et al. 2009. Cascades in Mediterranean submarine grand canyons. Oceanography, 22: 26-43.

Carroll, C., Johnson, D. S., Dunk, J. R., and Zielinski, W. J. 2010. Hierarchical Bayesian Spatial Models for Multispecies Conservation Planning and Monitoring. Conservation Biology, 24: 1538-1548.

Clarke, K., and Gorley, R. 2015. Getting started with PRIMER v7. PRIMER-E: Plymouth, Plymouth Marine Laboratory.

Coll, M., Palomera, I., Tudela, S., and Dowd, M. 2008. Food-web dynamics in the South Catalan Sea ecosystem (NW Mediterranean) for 1978-2003. Ecological Modelling, 217: 95-116.

Coll, M., Piroddi, C., Steenbeek, J., Kaschner, K., Lasram, F. B. R., Aguzzi, J., Ballesteros, E., et al. 2010. The biodiversity of the Mediterranean Sea: estimates, patterns, and threats. PloS one, 5: e11842.

Coll, M., Piroddi, C., Albouy, C., Ben Rais Lasram, F., Cheung, W. W. L., Christensen, V., Karpouzi, V. S., et al. 2012. The Mediterranean Sea under siege: spatial overlap between marine biodiversity, cumulative threats and marine reserves. Global Ecology and Biogeography, 21: 465-480.

Coll, M., Navarro, J., and Palomera, I. 2013. Ecological role, fishing impact, and management options for the recovery of a Mediterranean endemic skate by means of food web models. Biological Conservation, 157: $108-120$.

Coll, M., Steenbeek, J., Sole, J., Palomera, I., and Christensen, V. 2016. Modelling the cumulative spatialtemporal effects of environmental drivers and fishing in a NW Mediterranean marine ecosystem. Ecological Modelling, 331: 100-114.

Colloca, F., Cardinale, M., Maynou, F., Giannoulaki, M., Scarcella, G., Jenko, K., Bellido, J. M., et al. 2013. Rebuilding Mediterranean fisheries: a new paradigm for ecological sustainability. Fish and Fisheries, 14: 89-109.

Colloca, F., Garofalo, G., Bitetto, I., Facchini, M. T., Grati, F., Martiradonna, A., Mastrantonio, G., et al. 2015. The seascape of demersal fish nursery areas in the North Mediterranean Sea, a first step towards the implementation of spatial planning for trawl fisheries. PLoS One, 10: e0119590.

Costello, M. J., and Chaudhary, C. 2017. Marine Biodiversity, Biogeography, Deep-Sea Gradients, and Conservation. Current Biology, 27: R511-R527.

d’Onghia, G., Politou, C. Y., Bozzano, A., Lloris, D., Rotllant, G., Sión, L., and Mastrototaro, F. 2004. Deep-water fish assemblages in the Mediterranean Sea. Scientia Marina, 68: 87-99.

Damalas, D., Katsanevakis, S., Maravelias, C. D., Karageorgis, A. P., Anagnostou, C., Tsitsika, E., and Papaconstantinou, C. 2016. Habitat preferences and spatiotemporal distribution of four benthic skates in the eastern Mediterranean Sea.

De Juan, S., Thrush, S., and Demestre, M. 2007. Functional changes as indicators of trawling disturbance on a benthic community located in a fishing ground (NW Mediterranean Sea). Marine Ecology Progress Series, 334: 117-129. 
Demestre, M., Sanchez, P., and Abello, P. 2000. Demersal fish assemblages and habitat characteristics on the continental shelf and upper slope of the north-western Mediterranean. Journal of the Marine Biological Association of the United Kingdom, 80: 981-988.

Duffy, J. E. 2009. Why biodiversity is important to the functioning of real-world ecosystems. Frontiers in Ecology and the Environment, 7: 437-444.

Estrada, M. 1996. Primary production in the northwestern Mediterranean. Scientia Marina, 60: 55-64.

Ferretti, F., Worm, B., Britten, G. L., Heithaus, M. R., and Lotze, H. K. 2010. Patterns and ecosystem consequences of shark declines in the ocean. Ecology letters, 13: 1055-1071.

Fonseca, V. P., Pennino, M. G., de Nóbrega, M. F., Oliveira, J. E. L., and de Figueiredo Mendes, L. 2017. Identifying fish diversity hot-spots in data-poor situations. Marine Environmental Research, 129: $365-373$.

Font, J., Salat, J., and Julià, A. 1990. Marine circulation along the Ebro continental margin. Marine Geology, 95: $165-177$.

Gaertner, J. 2000. Seasonal organization patterns of demersal assemblages in the Gulf of Lions (northwestern Mediterranean Sea). Journal of the Marine Biological Association of the United Kingdom, 80: 777-783.

Gibson, R., Atkinson, R., and Gordon, J. 2005. Zonation of deep biota on continental margins. Oceanography and Marine Biology: An Annual Review, 43: 211-78.

Golding, N., and Purse, B. V. 2016. Fast and flexible Bayesian species distribution modelling using Gaussian processes. Methods in Ecology and Evolution, 7: 598-608.

Goñi, R., Quetglas, A., and Reñones, O. 2006. Spillover of spiny lobsters Palinurus elephas from a marine reserve to an adjoining fishery. Marine Ecology Progress Series, 308: 207-219.

Granger, V., Bez, N., Fromentin, J., Meynard, C., Jadaud, A., and Merigot, B. 2015. Mapping diversity indices: not a trivial issue. Methods in Ecology and Evolution, 6: 688-696.

Hauck, J. 2018. Unsteady seasons in the sea. Nature Climate Change: 1.

Hooper, D. U., Chapin, F., Ewel, J., Hector, A., Inchausti, P., Lavorel, S., Lawton, J., et al. 2005. Effects of biodiversity on ecosystem functioning: a consensus of current knowledge. Ecological monographs, 75: 3-35.

Kallianiotis, A., Sophronidis, K., Vidoris, P., and Tselepides, A. 2000. Demersal fish and megafaunal assemblages on the Cretan continental shelf and slope (NE Mediterranean): seasonal variation in species density, biomass and diversity. Progress in oceanography, 46: 429-455.

Lindgren, F. 2012. Continuous domain spatial models in R-INLA. The ISBA Bulletin, 19: 14-20.

Liquete, C., Piroddi, C., Drakou, E. G., Gurney, L., Katsanevakis, S., Charef, A., and Egoh, B. 2013. Current status and future prospects for the assessment of marine and coastal ecosystem services: a systematic review. PloS one, 8: e67737.

Lloret, J., Lleonart, J., Solé, I., and Fromentin, J.-M. 2001. Fluctuations of landings and environmental conditions in the north-western Mediterranean Sea. Fisheries Oceanography, 10: 33-50.

Magurran, A. E. 1988. Why diversity? In Ecological diversity and its measurement, pp. 1-5. Springer. 
Margalef, R. 1985. Key environments: Western Mediterranean. Key environments: Western Mediterranean. https://www.scopus.com/inward/record.uri?eid=2-s2.00022172754\&partnerID=40\&md5=eca056a7a9c16c836f2f34b2d679325f.

Martín, P., Muntadas, A., De Juan, S., Sánchez, P., and Demestre, M. 2014. Performance of a northwestern Mediterranean bottom trawl fleet: How the integration of landings and VMS data can contribute to the implementation of ecosystem-based fisheries management. Marine Policy, 43: 112-121.

Massutí, E., and Reñones, O. 2005. Demersal resource assemblages in the trawl fishing grounds off the Balearic Islands (western Mediterranean). Scientia Marina, 69: 167-181.

Maynou, F., Lleonart, J., and Cartes, J. E. 2003. Seasonal and spatial variability of hake (Merluccius merluccius L.) recruitment in the NW Mediterranean. Fisheries Research, 60: 65-78.

Maynou, F., Abelló, P., and Sartor, P. 2004. A review of the fisheries biology of the mantis shrimp, Squilla mantis (L., 1758) (Stomatopoda, Squillidae) in the Mediterranean. Crustaceana, 77: 1081-1099.

Mendoza, M., Garrido, D., and Bellido, J. M. 2014. Factors affecting the fishing impact on cartilaginous fishes in southeastern Spain (western Mediterranean Sea). Scientia Marina, 78: 10.

Moore, C. H., Harvey, E. S., and Van Niel, K. P. 2009. Spatial prediction of demersal fish distributions: Enhancing our understanding of species-environment relationships. In ICES Journal of Marine Science.

Morales-Nin, B., and Moranta, J. 2004. Recruitment and post-settlement growth of juvenile Merluccius merluccius on the western Mediterranean shelf. Scientia Marina, 68: 399-409.

Morfin, M., Fromentin, J.-M., Jadaud, A., and Bez, N. 2012. Spatio-temporal patterns of key exploited marine species in the Northwestern Mediterranean Sea. PloS one, 7: e37907.

Muñoz, F., Pennino, M. G., Conesa, D., López-Quílez, A., and Bellido, J. M. 2013. Estimation and prediction of the spatial occurrence of fish species using Bayesian latent Gaussian models. Stochastic Environmental Research and Risk Assessment, 27: 1171-1180.

Myers, N., Mittermeier, R. A., Mittermeier, C. G., Da Fonseca, G. A., and Kent, J. 2000. Biodiversity hotspots for conservation priorities. Nature, 403: 853.

Navarro, J., Coll, M., Cardador, L., Fernández, Á. M., and Bellido, J. M. 2015. The relative roles of the environment, human activities and spatial factors in the spatial distribution of marine biodiversity in the Western Mediterranean Sea. Progress in Oceanography, 131: 126-137.

Navarro, J., Cardador, L., Fernández, Á. M., Bellido, J. M., and Coll, M. 2016. Differences in the relative roles of environment, prey availability and human activity in the spatial distribution of two marine mesopredators living in highly exploited ecosystems. Journal of biogeography, 43: 440-450.

Olivar, M. P., Emelianov, M., Villate, F., Uriarte, I., Maynou, F., Álvarez, I., and Morote, E. 2010. The role of oceanographic conditions and plankton availability in larval fish assemblages off the Catalan coast (NW Mediterranean). Fisheries Oceanography, 19: 209-229.

Palomera, I., Navarro, J., Albo Puigserver, M., Coll, M., Barría, C., Corrales, X., López, N., et al. 2015. The ECOTRANS Project: unraveling the trophic pathways and energy transfer from small pelagic fish to 
top predators in the Mediterranean Sea. Integrated Marine Biogeochemistry and Ecosystem Research. http://hdl.handle.net/10261/139792.

Pauly, D., Christensen, V., Guénette, S., and Pitcher, T. J. 2002. Towards sustainability in world fisheries. Nature, 418: 689.

Pavoine, S., and Bonsall, M. 2011. Measuring biodiversity to explain community assembly: a unified approach. Biological Reviews, 86: 792-812.

Pennino, M. G., Muñoz, F., Conesa, D., López-Quílez, A., and Bellido, J. M. 2013. Modeling sensitive elasmobranch habitats. Journal of Sea Research, 83: 209-218.

Pennino, M. G., Paradinas, I., Illian, J. B., Muñoz, F., Bellido, J. M., López-Quílez, A., and Conesa, D. 2019. Accounting for preferential sampling in species distribution models. Ecology and evolution, 9: 653663.

Pinnegar, J., Polunin, N., Francour, P., Badalamenti, F., Chemello, R., Harmelin-Vivien, M.-L., Hereu, B., et al. 2000. Trophic cascades in benthic marine ecosystems: lessons for fisheries and protected-area management. Environmental Conservation, 27: 179-200.

Piroddi, C., Macias, D., Steenbeek, J., Buszowski, J., Greer, K., Coll, M., Danovaro, R., et al. 2017. Historical changes of the Mediterranean Sea ecosystem: modelling the role and impact of primary productivity and fisheries changes over time. Scientific Reports, 7: 44491.

Puerta, P., Hunsicker, M. E., Quetglas, A., Alvarez-Berastegui, D., Esteban, A., Gonzalez, M., and Hidalgo, M. 2015. Spatially Explicit Modeling Reveals Cephalopod Distributions Match Contrasting Trophic Pathways in the Western Mediterranean Sea. PLoS One, 10: e0133439.

Puerta, P., Quetglas, A., and Hidalgo, M. 2016. Seasonal variability of cephalopod populations: a spatiotemporal approach in the Western Mediterranean Sea. Fisheries Oceanography, 25: 373-389.

QGIS Development Team. 2012. QGIS Geographic Information System. Open Source Geospatial Foundation Project.

R Core Team. 2017. R: A language and environment for statistical computing [Internet]. Vienna, Austria; 2014.

Roos, M., and Held, L. 2011. Sensitivity analysis in Bayesian generalized linear mixed models for binary data. Bayesian Analysis, 6: 259-278.

Rue, H., Martino, S., Lindgren, F., Simpson, D., Riebler, A., and Krainski, E. 2009. INLA: functions which allow to perform a full Bayesian analysis of structured additive models using Integrated Nested Laplace Approximation. R package version 0.0.

Salat, J., Garcia, M. A., Cruzado, A., Palanques, A., Arín, L., Gomis, D., Guillén, J., et al. 2002a. Seasonal changes of water mass structure and shelf slope exchanges at the Ebro Shelf (NW Mediterranean). Continental Shelf Research, 22: 327-348.

Salat, J., Garcia, M. A., Cruzado, A., Palanques, A., Arín, L., Gomis, D., Guillén, J., et al. 2002b. Seasonal changes of water mass structure and shelf slope exchanges at the Ebro Shelf (NW Mediterranean). Continental Shelf Research, 22: 327-348. 
Saraux, C., Fromentin, J.-M., Bigot, J.-L., Bourdeix, J.-H., Morfin, M., Roos, D., Van Beveren, E., et al. 2014. Spatial structure and distribution of small pelagic fish in the northwestern Mediterranean sea. PloS one, 9: e111211.

Sardà, F., Cartes, J. E., and Albiol, A. 1998. A modified commercial trawl used to sample deep-sea megabenthos. Fisheries science, 64: 492-493.

Shannon, C. E., and Weaver, W. 1949. The mathematical theory of information.

Silveira Simão, D. 2013. Distribution and population biology of pelagic decapod crustaceans of the western Mediterranean.

Spiegelhalter, D. J., Best, N. G., Carlin, B. P., and Van Der Linde, A. 2002. Bayesian measures of model complexity and fit. Journal of the Royal Statistical Society: Series B (Statistical Methodology), 64: 583-639.

Steel, E. A., Kennedy, M. C., Cunningham, P. G., and Stanovick, J. S. 2013. Applied statistics in ecology: Common pitfalls and simple solutions. Ecosphere.

Tittensor, D. P., Mora, C., Jetz, W., Lotze, H. K., Ricard, D., Berghe, E. V., and Worm, B. 2010. Global patterns and predictors of marine biodiversity across taxa. Nature, 466: 1098.

Tsikliras, A. C., Dinouli, A., Tsiros, V.-Z., and Tsalkou, E. 2015. The Mediterranean and Black Sea fisheries at risk from overexploitation. PloS one, 10: e0121188.

Ward, P., and Myers, R. A. 2005. Shifts in open-ocean fish communities coinciding with the commencement of commercial fishing. Ecology, 86: 835-847.

Watanabe, S. 2010. Asymptotic equivalence of Bayes cross validation and widely applicable information criterion in singular learning theory. Journal of Machine Learning Research, 11: 3571-3594.

Wikle, C. K. 2003. Hierarchical Bayesian models for predicting the spread of ecological processes. Ecology, 84: $1382-1394$.

Worm, B., Barbier, E. B., Beaumont, N., Duffy, J. E., Folke, C., Halpern, B. S., Jackson, J. B., et al. 2006. Impacts of biodiversity loss on ocean ecosystem services. Science, 314: 787-790.

\section{Acknowledgements}

The authors would like to acknowledge all participants in the ECOTRANS project that helped in the sampling and laboratory work. This study forms a contribution to the project ECOTRANS (CTM201126333, Ministerio de Economía y Competitividad, Spain) and SafeNET (EU-DGMARE MARE/2014/41). Also, we would like to thank Xavier Corrales who helped in the interpretation of results. Joan Navarro was supported by Spanish National Program Ramón y Cajal. The authors acknowledge the Secretaria Pesca Maritima from Ministerio Agricultura, Pesca y Alimentación for providing access to VMS data.

\section{Author contributions}

Authors contributions: D.V., M.G.P. and M.C. designed the analysis; M.C., I.P., J.N. participated in the fieldwork. D.V. and M.G.P. carried out the statistical modelling with input from M.C. All authors contributed to the manuscript text. 